\title{
Caregiver Burden among Informal Caregivers of Rural Older Persons in Nepal
}

\author{
Khanal $\mathrm{B}^{1}$, Chalise $\mathrm{HN}^{2,3^{*}}$ \\ ${ }^{1}$ Registered Nurse Supervisor, Arcare Tagium Aged Care, Brisbane, Australia \\ ${ }^{2}$ Faculty Member, Department of Public Health, Nobel College affiliated to Pokhara University, Sinamangal, Kathmandu, Nepal \\ ${ }^{3}$ Geriatric Society of Nepal, Kathmandu, Nepal
}

Corresponding Author: Hom Nath Chalise

Address: Department of Public Health, Nobel College affiliated to Pokhara University, Sinamangal, Kathmandu, Nepal; Tel: +977 9851012622; Email: chalisehkpp@gmail.com

Received date: 29 July 2020; Accepted date: 06 September 2020; Published date: 20 September 2020

Citation: Khanal B, Chalise HN. Caregiver Burden among Informal Caregivers of Rural Elderly in Nepal. J Health Care and Research. 2020 Sept 20;1(3):149-56.

Copyright (C) 2020 Khanal B, Chalise HN. This is an open-access article distributed under the Creative Commons Attribution License, which permits unrestricted use, distribution, and reproduction in any medium, provided the original work is properly cited.

\begin{abstract}
Background: Today, people are living longer than ever before due to advances in education, technology, medicine, food distribution, and public health. Longevity has also resulted in a caregiving burden in the family living together. The purpose of this paper is to analyze the situation of the elderly caregiving burden in Nepal.

Methods: This is a cross-sectional study carried out in a rural area of Nepal. The total sample size for this study was 150 older persons 65 years and above. The caregiving burden was measured through the widely used scale Zarit Burden Interview (ZBI).

Results: Mean age of the care recipients (elderly) was $78.46( \pm 7.78)$ years and the mean age of the care provider was $46.6( \pm 46)$ years. The mean score of the caregiving burden was $12.89( \pm 5.7)$. The majority of the caregiver has reported little or no burden (88\%), 10\% mild to the moderate burden, 1.33\% moderate to severe burden and only one respondent (o.67\%) has reported severe burden. Marital status, ethnicity, religion, living arrangement, and functional limitations on activities on daily living were significant variables related to caregiving burden.

Conclusion: This study shows the caregiving burden is quite low among Nepalese care providers living in a rural area. Given the growing number of elderly people, there is an urgent need to care for the wellbeing of dependent older people and their families.
\end{abstract}

\section{Keywords}

Care Giving Burden, Zarit Burden Interview (ZBI), Functional Limitations, Activities of daily livings (ADLs), Instrumental Activities of Daily Livings (IADLs), Rural Elderly, Nepal

\section{Introduction}

In almost every country, the proportion of people aged over 60 years is growing faster than any other age group, as a result of both longer life expectancy and declining fertility rates. The size of the older population 60 years and above is expected to grow to 2 billion by 2050 [1]. Rapid population aging is a global phenomenon, regardless of a nation's level of development [2]. Today, people are living longer than ever before due to advances in education, technology, medicine, food distribution, and public health [3]. This population trend can be seen as a success story for 
public health policies and for socio-economic development, but it also challenges society to provide the necessary care and maintain an optimal quality of life $[1,3]$.

Caregiving is defined as the process of undertaking the activities and responsibilities of caregiving which involves different types of support like emotional, physical, and financial support [4]. Informal caregivers of the elderly are defined as people who provide unpaid care for the elderly. The care may be in the form of physical, emotional, social, and financial assistance. Generally, such care is provided by family members of the same family to whom care is provided. The caregiver burden is identified as a state resulting from providing the necessary care to an impaired older adult but that threatens either the physical or psychological wellbeing of the caregiver [5]. One of the populations most vulnerable to the burden caused by providing long-term care are spouses, who often view caring as an extension of their marital commitment, and who are more likely to continue caring despite the limited support services available to them, or the emotional suffering they experience [6]. Nevertheless, the difficulties experienced by caregivers have often considered only after the signs of burnout are apparent. These signs indicate the progression of caregiver burden to the point where the experience is no longer a viable or healthy option for either the caregiver or the person receiving care [5].

Social science researchers have identified two types of home caregivers for older persons and categorized by scholars in studies as professional care and personal care [7]. Professional care is skilled care provided by a nurse, physical therapist, occupational therapist, speech therapist, or social worker. Personal care is provided by family members or workers at home, which is structurally based on gender relations whereby women take the responsibility for home care. Caregivers' burden predicts the physical and mental health outcomes of dependent older people and their caregivers [8]. Informal caregiving demands substantial effort, productive time, and financial resources of caregivers. With extended hours of caregiving, caregivers may develop sleep disturbance, depression, and chronic diseases. Thus, the provision of informal caregiving proceeds at the expense of caregivers' wellbeing. The declining wellbeing of caregivers can lead to poor care of the dependent older people. Neglecting to address the informal caregivers' burden may eventually lead to ineffective care of the disabled older people [9].

\section{The situation in Nepal:}

Individuals 60 years and older are considered elderly. In recent decades the elderly population growth rate is higher than the total population growth rate [10] and the life expectancy of the elderly also increasing rapidly [11]. All these results the demand for caregiving is increasing to older adults. Studies show more than $80 \%$ of the elderly live with their children and taking care of the elderly is considered the responsibility of family members [12]. In Nepal, the family, as a social institution, is the main source of support and care for its older members, helping them with day-to-day activities and giving them all kinds of support. Traditional family values, including revering elders, and providing care and support to the elderly is considered a social norm and a moral duty for family members. Anecdotal evidence suggests that most primary caregiving is provided by either wife or daughter-in-law. Daughter's once they get married they move to the husband's home and taking care of the husband's family is considered their major duty and responsibility. As there is no formal care system of the elderly developed [13], still parents directly or indirectly think children as insurance for old age. Culturally taking care of older parents is considered a responsibility of children mainly sons [14]. But, recently with the nucleation of family and permanent migration of son's family to foreign countries daughter's taking care of their parents are also increasing.

However, with the increase in women's participation in the workforce, nucleation of family, and the effect of modernization, traditional family caregivers are facing different types of problems. Alternatively, there are few old age homes run by the government, charitable organizations, and the private sector in Nepal. The total number of elderly living in such an organization is less than in 2000 [15]. The number of private old age home are increasing recently $[16,17]$ with the 
increase of out-migration of Nepalese youths. But, the health status of elderly living in old age homes is not satisfactory $[18,19]$.

Providing care of older parents by family members is considered as a part of cultural norms in Nepali society [14]. There are no studies so far in Nepal to assess the situation of caregiving burden. This paper tries to analyze the situation of the care giving burden of Nepalese main care givers living in rural Nepal.

\section{Methodology}

This is a cross-sectional study carried out in 2011 in a village named Khanalthok of Kavrepalanchok district of Nepal. It is about $45 \mathrm{KM}$ east from Kathmandu, which is a hilly area of 12,423 square kilometers, which consisted of 10740 populations as of the 2001 census of Nepal. It has a mixed population of different caste and ethnic groups. This place is chosen conveniently by the researcher. Census of all the households having elderly who were 65 years and older living with others were surveyed for this purpose. There were a total of 189 households eligible for this study. Further, other inclusion criteria for this study were the main caretaker providing care of the elderly at least for the last six months and caretakers who can understand and respond in the Nepali language. Respondents for this study were the main caretaker of the elderly. Among 189 eligible households, there were only 179 main caretakers who can understand and respond in the Nepali language and a total of 174 were taking care of the elderly at least for the last six months. 9 respondents did not provide consent to participate, 11 respondents did not complete the interview. While cleaning the data four respondents had incomplete information about care burden information. Finally, 150 respondents were included in this study.

The questionnaire included general sociodemographic, activities of daily living, and caregiving burden instruments. To ensure the questionnaire's quality and sensitivity, the activity of daily living (ADL) scale and caregiving burden were translated into Nepali from English and then back-translated into English by English language teachers proficient in both languages. Different people conducted back translation. A pilot study of 31 respondents from the non-study area was conducted to identify potential problems with the questionnaire.

\section{Measurements}

The functional disability of older adults in Activities of Daily Living (ADL) was measured using a five-item scale (bathing, dressing, toileting, transferring, and eating) developed from the six-item ADL scale [20]. For the present study, responses were dichotomized as 'unable to do at all/need some help' and 'without help'. The internal consistency reliability of the ADL scale was 0.71 in this study. This scale is already used in Nepal with internal consistency reliability of 0.87 [21].

The caregiving burden was measured through the widely used scale Zarit Burden Interview [22]. Burden Inventory of Zarit et al. is the most established tool that measures the perceived burden of family caregivers. The inventory consists of 22 questions on a 5-point Likert Scale. Each question has 5 choices given scores as "never (0), almost (1), sometimes (2), often (3), and always (4)". Total scores indicate the caregiving burden. For the present study, internal consistency reliability was 0.77 which shows it has good internal consistency.

The SPSS 17 software was used to analyze the data with descriptive and inferential statistics such as Pearson correlation, analysis of variance (ANOVA), and independent t-test depending on the nature of the variable.

Approval for this study was obtained from the Asian College of Advance Studies, Purbanchal University in 2010. Further verbal consent from the authority of the concerned village was also obtained. Verbal informed consent was obtained from all the respondents for this study.

\section{Results}

Table-1 shows the general characteristics of the study population. The mean age of the care recipients (elderly) was $78.46( \pm 7.78)$ years. The mean age of the care provider was $46.6( \pm 46)$ years with an age range of 21-70 years. More than four-fifth care providers were female (80.7\%), married (87.3\%), Majority were Hindus religion (74.0\%), from Brahmin/Chhetri 
Citation: Khanal B, Chalise HN. Caregiver Burden among Informal Caregivers of Rural Elderly in Nepal. J Health Care and Research. 2020 Sept 20;1(3):149-56.

(72.0\%) ethnic groups, Literate $(52.7 \%)$. Among the main care providers, more than half $(56.0 \%)$ were daughter-in-laws, spouse (22.7\%), son (16.7\%), and brother/sister $(4.7 \%)$. The average size of the family was $7.69( \pm 3.21)$ and duration of care provided was $5.18( \pm 3.51)$ years. Functional limitations on at least one ADL activities were $30.0 \%$.

\begin{tabular}{|c|c|c|c|c|c|c|}
\hline \multicolumn{7}{|c|}{ Table-1: General characteristics of care providers and few information of care recipients } \\
\hline \multicolumn{2}{|c|}{ Variables } & \multirow{2}{*}{ Number } & \multirow{2}{*}{ Percentage } & \multirow{2}{*}{$\begin{array}{c}\text { Mean } \\
46.6\end{array}$} & \multirow{2}{*}{$\begin{array}{c}\text { SD } \\
\pm 13.8 \\
\end{array}$} & \multirow{2}{*}{$\begin{array}{c}\text { Range } \\
21-70\end{array}$} \\
\hline Age & & & & & & \\
\hline \multirow{2}{*}{ Sex } & Male & 29 & $19 \cdot 3$ & & & \\
\hline & Female & 121 & 80.7 & & & \\
\hline \multirow{2}{*}{ Marital Status } & Married & 131 & $87 \cdot 3$ & & & \\
\hline & Single & 19 & 12.7 & & & \\
\hline \multirow{2}{*}{ Ethnicity } & Brahmin/Chhetri & 108 & 72 & & & \\
\hline & Others & 42 & 28 & & & \\
\hline \multirow{3}{*}{ Religion } & Hindu & 111 & 74 & & & \\
\hline & Buddhist & 23 & $15 \cdot 3$ & & & \\
\hline & Christian & 16 & 10.7 & & & \\
\hline \multirow{2}{*}{ Education } & Literate & 79 & 52.7 & & & \\
\hline & Illiterate & 71 & $47 \cdot 3$ & & & \\
\hline \multirow{4}{*}{ Relationship with Elderly } & Son/Daughter & 25 & 16.7 & & & \\
\hline & Daughter-in-law & 84 & 56 & & & \\
\hline & Brother/sister & 7 & 4.7 & & & \\
\hline & Spouse & 34 & 22.7 & & & \\
\hline Size of family & & & & 7.69 & \pm 3.21 & Feb-15 \\
\hline \multirow{2}{*}{ Living arrangement } & Jointly with other family member & 138 & 92 & & & \\
\hline & Only with care recipients & 12 & 8 & & & \\
\hline Duration of care & & & & 5.18 & \pm 3.5 & Jan-15 \\
\hline \multirow{2}{*}{ ADL limitations } & No limitations & 105 & 70 & & & \\
\hline & Dependent on at least one ADL & 45 & 30 & & & \\
\hline Age & (Older persons) & & & 78.46 & \pm 7.78 & $65-94$ \\
\hline
\end{tabular}

Table-2 shows the situation of caregiving burden classified as Burden level measured through the Zarit Burden Interview scale. The mean score of the caregiving burden was $12.89( \pm 5.7)$ with a range of burdens 1 to 65 . Among the majority of the caregivers has reported little or no burden (88\%), mild to moderate burden (10\%), moderate to severe burden $(1.33 \%)$, and only one respondent (0.67\%) has reported severe burden.

Table-3 shows the associations of caregiving burden with socio-demographic variables. Age of care provider, duration of care, age of care recipients, and family size have no effect on the caregiving burden of respondents. The female caregiver has a slightly higher (12.45) burden index than the male caregiver (11.99). Further, it shows, single (widow/widower) caregiver has higher caregiving burden (16.21) than married (11.95), Others ethnic groups (16.33) has higher burden than Brahmin/Chhetri (10.89). The caregiving burden was higher for Christian (17.50) than Buddhists (12.56) and Hindus (11.49). The caregiving burden was high to those who were living only with care recipients (15.81) than other family members 
Citation: Khanal B, Chalise HN. Caregiver Burden among Informal Caregivers of Rural Elderly in Nepal. J Health Care and Research. 2020 Sept 20;1(3):149-56.

\section{Original Article}

(12.01). Similarly elderly with functional limitations had a high burden (13.98) than without functional limitations (10.85).

\section{Discussions}

Globally demographic shifts in the population of older adults have led to an increased interest in research on aging and also caregiving burden. Elderly populations are increasing rapidly in Nepal too $[10,12]$ and will increase in the coming days as well [23]. In Nepal, children are considered insurance for old age, and Norms of filial responsibility govern intergenerational relationships [14]. This is the first study carried out in Nepal that assesses the caregiving burden of Nepalese taking care of the older population. The caregiving burden was assessed through the Zarit Burden Interview which is one of the most commonly used instruments to assess the caregiving burden.

Table-2: Care giving burden perceived by Nepalese care giver in rural Nepal

\begin{tabular}{|l|l|c|c|}
\hline \multicolumn{4}{|c|}{ Table-2: Care giving burden perceived by Nepalese care giver in rural Nepal } \\
\hline Zarit Burden Scale Score & Interpretation of burden level & Number & Percentage \\
\hline 0-20 & Little or no burden & 132 & 88 \\
\hline $21-40$ & mild to moderate & 15 & 10 \\
\hline $41-60$ & moderate to severe & 2 & 1.33 \\
\hline $61-88$ & Severe & 1 & 0.67 \\
\hline Overall Score & Mean $=12.89( \pm 5.7)$ & Range 1-65 \\
\hline
\end{tabular}

\begin{tabular}{|c|c|c|c|c|}
\hline \multicolumn{5}{|c|}{ Table 3: Associations of care giving burden with socio-demographic variables } \\
\hline \multicolumn{2}{|c|}{ Variables } & \multirow[t]{2}{*}{ Number } & \multirow[t]{2}{*}{$\begin{array}{c}\text { Mean ZBI } \\
\text { score } \\
\end{array}$} & \multirow{2}{*}{$\begin{array}{c}\text { Correlation coefficient } \\
0.047\end{array}$} \\
\hline Age (Care giver) & & & & \\
\hline \multirow{2}{*}{ Sex } & Male & 29 & 11.99 & 0.034 \\
\hline & Female & 121 & 12.45 & \\
\hline \multirow{2}{*}{ Marital Status } & Married & 131 & 11.95 & $0.248^{* *}$ \\
\hline & Single & 19 & 16.21 & \\
\hline \multirow{2}{*}{ Ethnicity } & Brahmin/Chhetri & 108 & 10.89 & $0.443^{* *}$ \\
\hline & Others & 42 & 16.33 & \\
\hline \multirow{3}{*}{ Religion } & Hindu & 111 & 11.49 & $0.304^{* *}$ \\
\hline & Buddhist & 23 & 12.56 & \\
\hline & Christian & 16 & 17.5 & \\
\hline \multirow{2}{*}{ Education } & Literate & 79 & 12.95 & -0.002 \\
\hline & Illiterate & 71 & 12.8 & \\
\hline \multirow{4}{*}{$\begin{array}{l}\text { Relationship with } \\
\text { Elderly }\end{array}$} & Son/Daughter & 25 & 13.78 & 0.066 \\
\hline & Daughter-in-law & 84 & 11.25 & \\
\hline & Brother/sister & 7 & 16.05 & \\
\hline & Spouse & 34 & 12.98 & \\
\hline Size of family & & & & 0.008 \\
\hline \multirow{2}{*}{ Living arrangement } & Jointly with other family member & 138 & 12.01 & $0.179^{*}$ \\
\hline & Only with care recipients & 12 & 15.81 & \\
\hline Duration of care & & & & 0.031 \\
\hline \multirow{2}{*}{ ADL limitations } & No limitations & 105 & 10.85 & $0.218^{* *}$ \\
\hline & At least one limitations & 45 & 13.98 & \\
\hline Age & (Elderly age) & & & 0.031 \\
\hline Total & & 150 & 12.89 & \\
\hline
\end{tabular}


In this study mean age of elderly care recipients' was $78.46( \pm 7.78)$ years and the mean age of the care providers' was $46.6( \pm 46)$ years. More than four-fifth care providers were women $(80.7 \%)$ more than half (56.0\%) were daughter-in-laws. Studies from many other countries also show that the main caregivers of the elderly were women [24-27]. Daughters-in-law were the caregivers in a significant number of households in our study, as found in studies in India [28-30].

The mean score of ZBI was $12.89 \pm 5.7$ in this study. This score shows the caregiving burden of Nepalese care providers is quite low when compared with other studies. A study carried out in India shows the mean total score of ZBI was 17.9 [9]. A study from rural Egypt shows the caregiving burden was $35 \pm 14$ [25]. A meta-analysis, which included 58 studies that used the Zarit Burden Interview, reported a mean burden level of $29.9 \pm 9.3$ [26], suggesting that the caregivers in this study were very little burdened than those in a variety of other caregiving studies.

Further classification of the ZBI burden score shows the majority of the caregiver has reported little or no burden (88\%), 10\% had mild to the moderate burden, $1.33 \%$ had moderate to severe burden and only one respondent (0.67\%) had a severe burden. A recent study from Myanmar shows 21.5\% had experienced severe burden, 39.5\% had experienced moderate burden, 32.5\% had experienced mild burden and only $6.5 \%$ had experienced no/little burden.

This study found a Caregiving burden reported by Nepali care providers is quite low. This creates some doubt about the level of burden reported. There are some traditional ideals held by the Hindu religion that providing services to older people and parents are considered as a duty of other family members [14]. Further, many parents think children as insurance for old age as there is no well-developed formal system of social security [13]. Another possible reason may be care was provided jointly by other family members also as the majority of care providers were living in large family size.

This study found caregiver who was living only with care recipients had experienced higher caregiving burden compared to with living with other family members. It may be due to not having other people to provide care to the elderly. Further caregiver whose marital status was single (including widow/widower) has a higher caregiving burden compared with a married caregiver. Other research shows married caregivers or spousal caregivers had higher mean burden scores than single caregivers or other family members [31,32] Single caregiver (widow/widower) reporting higher caregiving burden in Nepal maybe they did not get proper support from other family members and lower status in the family due to not having a spouse.

Major ethnic groups of this study area were $72 \%$ Brahmin-Chhetri and 28\% were others that included (Tamang/Newar/Dalits etc.). The major religions of the respondents were Hindu, Buddhist, and Christian. This study found ethnicity and religion were a significant variable of caregiving burden. BrahminChhetri ethnic groups and Hindu religion followers have expressed a lower caregiving burden than other ethnicity and Christians. There was a very high correlation $(\mathrm{r}=0.698)$ between ethnicity and religion in this study. Many studies show that ethnicity is related to caregiving burden [33].

This study found functional limitations on at least one ADLs is 30\%. This is quite high when compared with previous study of Nepal [21]. This study also found elderly having functional limitations was correlated with a higher caregiving burden. Many other studies carried out in other different countries also show care given burden was highly correlated with functional limitations [28-30].

Besides some interesting findings, it is important to address the limitations of this study. First, this study is a cross-sectional study, thus the results cannot establish causal relationships of the study variables. Second, this data comes from one community of one district and includes only a few ethnicities so the results may not be able to be generalized to other castes, ethnicities, and populations. Third, this study did not measure the nature of social support provided to the elderly and other heal related implications to 
care providers.

Despite the limitations, the findings of this study suggest that Nepalese elderly caregivers report very little caregiving burden. This indicates that the norm of filial piety and responsibility is strong in Nepalese culture. Further qualitative research is needed to explore the real situation of the caregiving burden of Nepalese older people. This may contribute to the empowerment of the elderly, and thus, enhance their QOL of both care providers and care recipients in the future.

\section{Conclusions}

Caregiver burden is a significant issue for those who care for elderly family members. Although this study shows the caregiving burden is quite low. In view of the growing number of elderly people, there is an urgent need to care for the wellbeing of dependent older people and their families.

\section{Conflict of Interest}

All authors have read and approved the final version of the manuscript. The authors have no conflicts of interest to declare.

\section{Funding}

This work has not been funded by any institution or organization.

\section{References}

[1] Global Health Ethics - Aging. World Health Organization. [Cited 2020 July 16]. Available from: https://www.who.int/ethics/topics/ageing/en/

[2] Chalise HN. Aging: basic concept. Am J Biomed Sci \& Res. 2019 Jan 2;1(1):8-10.

[3] Chalise HN, Rosenberg E. Social and Health Status of Community-Dwelling Older Adults in Nepal. Advances in Aging Research. $2019 \mathrm{Jul}$ 31;8(4):63-74.

[4] Salama R. Caregiver burden from caring for impaired elderly: a cross-sectional study in rural Lower Egypt. Italian Journal of Public Health. 2012;9(4).

[5] Zarit SH, Todd PA, Zarit JM. Subjective burden of husbands and wives as caregivers: a longitudinal study. Gerontologist. 1986 Jun;26(3):26o-66. [PMID:
3721233]

[6] Perry J, O'Connor D. Preserving personhood: (Re) membering the spouse with dementia. Family Relations. 2002 Jan;51(1):55-62.

[7] Abdelmoneium AO, Alharahsheh ST. Family home caregivers for old persons in the Arab region: perceived challenges and policy implications. Open Journal of Social Sciences. 2016 Jan 14;4(1):151-64.

[8] Carretero S, Garcés J, Ródenas F, Sanjosé V. The informal caregiver's burden of dependent people: theory and empirical review. Arch Gerontol Geriatr. 2009 Jul-Aug;49(1):74-79. [PMID: 18597866]

[9] Brinda EM, Rajkumar AP, Enemark U, Attermann J, Jacob KS. Cost and burden of informal caregiving of dependent older people in a rural Indian community. BMC Health Serv Res. 2014 May 7;14:207. [PMID: 24886051]

[10] Chalise HN. Provincial situation of elderly population in Nepal. Am J Aging Sci Res. 2020;1(1): 9-11.

[11] Chalise HN, Ghimire-Risal PK. Does Population Ageing Affect the Least Developed Country Like Nepal?. Geriatrics. 2018;44(3):299-14.

[12] Chalise HN, Brightman JD. Aging trends: Population aging in Nepal. Geriatrics \& Gerontology International. 2006 Sep;6(3):199-204.

[13] Malakar I, Chalise HN. Perception of Elderly towards Social Security Allowance in Nepal. South Asian Journal of Social Studies and Economics. 2018: 1-9.

[14] Chalise HN, Saito T, Takahashi M, Kai I. Relationship specialization amongst sources and receivers of social support and its correlations with loneliness and subjective well-being: A cross sectional study of Nepalese older adults. Archives of gerontology and geriatrics. 2007 May 1;44(3):299-14.

[15] Dhital S, Chalise HN, Rupakheti D. Migration, ageing and spousal separation: A review of current population trend in Nepal. J J Geronto. 2015;1(1):1-7.

[16] Rai S, Khanal P, Chalise HN. Elderly abuse experienced by older adults prior to living in old age homes in Kathmandu. J Gerontol Geriatr Res. 2018;7(1):460.

[17] Khanal P, Rai S, Chalise H. Children's migration and its effect on elderly people: A study at old age homes in Kathmandu. Am J Gerentol Geriatr. 2018;1(1):1001. 
[18] Chalise HN. Depression among elderly living in Briddashram (old age home). Advances in Aging Research. 2014 Feb 6;3(1):6-11.

[19] Mishra S, Chalise HN. Health Status of Elderly Living in Briddaashram (Old Age Home). Int J Pub Health Safe. 2019;4:172.

[20] Katz S, Ford AB, Moskowitz RW, Jackson BA, Jaffe MW. Studies of Illness in the Aged. The Index of Adl: A Standardized Measure Of Biological And Psychosocial Function. JAMA. 1963 Sep 21;185:914-19. [PMID: 14044222]

[21] Chalise HN, Saito T, Kai I. Functional disability in activities of daily living and instrumental activities of daily living among Nepalese Newar elderly. Public Health. 2008 Apr;122(4):394-96. [PMID: 17888469] [22] Zarit S, Orr NK, Zarit JM. The hidden victims of Alzheimer's disease: Families under stress. NYU press; 1985 .

[23] Chalise HN. Demographic Window of Opportunity in Nepal. Nepal Population Journal. 2018 Dec 31;18(17):133-40.

[24] Naing MZ, May SY, Aung MH. Caregiver burden from caring for dependent elderly in Yangon, The Republic of the Union of Myanmar. Makara J Health Res. 2020;24(1):3.

[25] Salama R. Caregiver burden from caring for impaired elderly: a cross-sectional study in rural Lower Egypt. Italian Journal of Public Health. 2012;9(4).

[26] Pinquart M, Sörensen S. Ethnic differences in stressors, resources, and psychological outcomes of family caregiving: a meta-analysis. Gerontologist. 2005
Feb;45(1):90-106. [PMID: 15695420]

[27] Badaru UM, Ogwumike OO, Adeniyi AF, Nelson EE. Determinants of caregiving burden and quality of life of informal caregivers of African stroke survivors: literature review. Int J Disabil Hum Dev. 2017 Aug 28;16(3):249-58.

[28] Gupta R, Pillai VK, Levy EF. Relationship quality and elder caregiver burden in India. Journal of Social Intervention: Theory and Practice. 2012 Jun 22;21(2):39-62.

[29] Sabzwari S, Badini AM, Fatmi Z, Jamali T, Shah S. Burden and associated factors for caregivers of the elderly in a developing country. East Mediterr Health J. 2016 Sep 25;22(6):394-403. [PMID: 27686980]

[30] Lee M, Yoon E, Kropf NP. Factors affecting burden of South Koreans providing care to disabled older family members. Int $\mathrm{J}$ Aging Hum Dev. 2007;64(3):245-62. [PMID: 17503688]

[31] Lolaty HA, Ramezani A, Bastani F, Haghani H. Family caregivers burden and its related factors among iranian elderly psychiatric patients' caregivers. Iran J Psychiatry Behav Sci. 2018;12(2):e9311.

[32] Pinquart M, Sörensen S. Differences between caregivers and noncaregivers in psychological health and physical health: a meta-analysis. Psychol Aging. 2003 Jun;18(2):250-67. [PMID: 12825775]

[33] Rote SM, Angel JL, Moon H, Markides K. Caregiving Across Diverse Populations: New Evidence From the National Study of Caregiving and Hispanic EPESE. Innovation in Aging. 2019 May;3(2):igzo33. 